\title{
Development of Dried Chili Paste with Added Indigenous Herbs from Conserved Area of Plant Genetic Conservation at Kanchanaburi Province $^{\dagger}$
}

\section{Rungrat CHAMCHAN, Somsri CHAROENKIATKUL, Parunya THIYAJAI, Worarat SUWANWATTANA, Uthaiwan SUTTISANSANEE, Warangkana SRICHAMNONG, Nattira ON-NOM*}

\author{
Institute of Nutrition, Mahidol University, Phuttamonthon, Nakorn Pathom 73170, Thailand
}

('Corresponding author's e-mail: nattira.onn@mahidol.ac.th)

Received: 29 March 2018, Revised: 8 June 2018, Accepted: 26 August 2018

\begin{abstract}
The objectives of this research were to serve Plant Genetic Conservation Project under the Royal Initiative of Her Royal Highness Princess Maha Chakri Sirindhorn (RSPG) and to promote the use of indigenous plants growing in Kanchanaburi province to be used in the production of healthy food. The main research activity of this study was to develop dried chili paste made with grilled fish by adding local herbs which are Wan-Prao-Hom (Kaempferia roscoeana Wall.), Kra-Chai-Pran (Zingiber citriodorum J. Mood \& T. Theleide), Ka-Pa (Alpinia malaccensis (Burm.f.) Roscoe.) and Plai (Zingiber cassumunar Roxb.). These plants were all identified as indigenous plants. The sensory evaluations were conducted with a 5-point hedonic scale and within the recommended guidelines. The total phenolic compounds were determined and the antioxidant activities of the product were also analyzed via DPPH and ORAC assays. The sensory evaluation score showed that dried chili paste containing $3.7 \%$ chili obtained higher overall liking score than product containing $5.4 \%$ chili. The water activity of product was 0.34 which was in line with the standard protocol of the Thai community. For nutritional values, it presented that one serving size (12 g) of product provided $23 \mathrm{kcal}$ of energy, $4.95 \mathrm{~g}$ of protein, $0.48 \mathrm{~g}$ of fat, $1.35 \mathrm{~g}$ of fiber and 403 $\mathrm{mg}$ of sodium. Moreover, the dried chili paste with added indigenous herbs from RSPG at Kanchanaburi had higher total phenolic compounds and antioxidant activities than the herbals chili powder with grinded spices product. According to consumer acceptability test, the acceptability level was $92 \%$, while $88 \%$ said that they would like to buy the product. Therefore, this research can serve as a prototype to develop other local foods having suitable tastes and health-enhancing benefits. Finally, the research may help to create job opportunities and generate the income for people living in the community.
\end{abstract}

Keywords: Dry chili paste, local herbs, Kanchanaburi Province, Plant genetic conservation project

\section{Introduction}

Dried chili paste made with grilled fish or nam prik pla yang is very popular among Thai people. The main ingredients of dried chili paste made with grilled fish are chili, garlic, shallot and grilled fish. It can be produced easily. However, the flavor of dried chili paste also depends on the local ingredients that have been added. Dried chili paste is one of the most popular existing local cuisines in Kanchanaburi province. This is due to their special flavor which comes from dill fruit [1]. Nowadays, people are more

\footnotetext{
${ }^{\dagger}$ Presented at the International Conference on Biomedical Sciences 2018: March 22 ${ }^{\text {nd }}-23^{\text {rd }}, 2018$
} 
http://wjst.wu.ac.th

aware of how certain foods affect their health and would like to have food with health benefits, focusing on natural antioxidants. Thailand has many verities of herbs which have functional properties.

Wan-Prao-Hom (Kaempferia roscoeana Wall.), Kra-Chai-Pran (Zingiber citriodorum J. Mood \& T. Theleide), Ka-Pa (Alpinia malaccensis (Burm.f.) Roscoe.) and Plai (Zingiber cassumunar Roxb.) are the local herbs which can be found in Kanchanaburi province especially in Plant Genetic Conservation Project Under the Royal Initiation of Her Royal Highness Princess Maha Chakri Sirindhorn (RSPG) area. These plants have been regarded as medicinal plants and they are used as Thai folk medicine against various diseases such as diabetes, cancer, herpes, malaria, wound infection, urticarial and allergy [2-4]. Moreover, Wan-Prao-Hom (Kaempferia roscoeana Wall.), Kra-Chai-Pran (Zingiber citriodorum J. Mood \& T. Theleide), Ka-Pa (Alpinia malaccensis (Burm.f.) Roscoe.) and Plai (Zingiber cassumunar Roxb.) are used as a spice and food in Thai cuisine.

Phytochemical and antioxidant properties studies of Kaempferia, Zingiber, Alpinia species showed that in leave and rhizomes have phenolic content and antioxidant activity [5]. Moreover, Chan, Lim and Wong (2011) presented that leave has higher total phenolic content and antioxidant activities than rhizomes [6-10]. According to Somsri et al. (2014), total phenolic content and actioxidant acitivities by ORAC and DPPH assay of Wan-Prao-Hom (Kaempferia roscoeana Wall.), Kra-Chai-Pran (Zingiber citriodorum J. Mood \& T. Theleide), Ka-Pa (Alpinia malaccensis (Burm.f.) Roscoe.) and Plai (Zingiber cassumunar Roxb.) had been determined. The results showed that Wan-Prao-Hom has highest total phenolic content and antioxidant activities follow by plai, Ka-pa and Kra-Chai-Pran, respectively [1].

Therefore, this research aimed to serve Plant Genetic Conservation Project under the Royal Initiative of Her Royal Highness Princess Maha Chakri Sirindhorn (RSPG) and develop dried chili paste made with grilled fish by adding local herbs which are Wan-Prao-Hom (Kaempferia roscoeana Wall.), Kra-Chai-Pran (Zingiber citriodorum J. Mood \& T. Theleide), Ka-Pa (Alpinia malaccensis (Burm.f.) Roscoe.) and Plai (Zingiber cassumunar Roxb.) in order to improve the potential health benefits of the product.

\section{Materials and methods}

\section{Materials}

Fresh local herbs which are Wan-Prao-Hom, Kra-chai-Pran, Ka-Pa and Plai were received from the area of Khuean Srinagarindra National Park, Kanchanaburi Province. The local herbs were cleaned and dried using a hot air oven at $60{ }^{\circ} \mathrm{C}$ for $4-5 \mathrm{~h}$. The dried herbs were ground up. Then, the ground herbs were vacuum packed and kept at $4{ }^{\circ} \mathrm{C}$. Other spices and seasoning were purchased from a local market in Kanchanaburi. All chemical reagents were of analytical reagent grade.

\section{Preparation of dried chili paste with local herbs}

The dried chili paste's ingredients are shown in Table 1. The protocol of dried chili paste preparation was given from housewife group of Song Pi Nong community, Kanchanaburi province. The dried chili paste with local herbs was prepared by roasting shallots, garlic, dill fruit and chili in an oven at $100{ }^{\circ} \mathrm{C}$ for $30 \mathrm{~min}$. After that, it was blended at a level 3 speed for $4 \mathrm{~min}$. Then ground grilled fish and ground local herbs were added to the mixture and were blended for 1 more minute. The mixture was fried in a pan for $5 \mathrm{~min}$, and all the seasonings were added to obtain the dried chili paste with local herbs. The dried chili paste with local herbs was packed into a sterilized glass bottle and used in the following experiments. 
Table 1 Formulations of the ingredients used for dried chili paste with added local herbs.

\begin{tabular}{lcc}
\hline Ingredients (\%) & Formula A & Formula B \\
\hline Bird chili & 3.8 & 2.7 \\
Ground chili & 1.6 & 1.0 \\
Ground grilled fish & 34.4 & 34.4 \\
Garlic & 23.9 & 23.9 \\
Shallots & 19.2 & 21.0 \\
Tamarind paste & 2.8 & 2.8 \\
Salt & 4.4 & 4.4 \\
Sugar & 7.2 & 7.2 \\
Dill fruit & 0.1 & 0.1 \\
Ground Wan-Prao-Hom & 1.0 & 1.0 \\
Ground Kra-Chai-Pran & 1.0 & 1.0 \\
Ground Ka-Pa & 0.5 & 0.5 \\
Ground Plai & 0.1 & 0.1 \\
\hline
\end{tabular}

\section{Physical analysis}

Water activity of the dried chili paste with local herbs was determined by following Suriya and Worasuwanaruk (2016) [11]. Water activity meter set $A_{w}$ (model ms1, Novasina, Switzerland) was used in this study. Triplicate samples were measured at $24 \pm 1{ }^{\circ} \mathrm{C}$.

\section{Nutritional values analysis}

The dried chili paste with local herbs was analyzed on moisture content, ash, protein, fat, carbohydrate, fiber and minerals by standard method of AOAC (2016) [12]. The calorie content was calculated based on the contents of protein, fat and carbohydrate.

Total phenolic compounds and antioxidant activity analysis

The fresh dried chili paste with local herbs sample was briefly extracted in $70 \%$ ethanol and left to stand at room temperature (approximately $25 \pm 1^{\circ} \mathrm{C}$ ) for $2 \mathrm{~h}$, then centrifuged at $8,000 \mathrm{rpm}$ for $15 \mathrm{~min}$. The clear supernatant was separated for the analysis of total phenolic compounds using the Folin-Ciocalteu colorimetric method [13] and antioxidant activity using the DPPH (2, 2- diphenyl-1-picryl-hydrazyl) method using different concentrations of Trolox solution as the standard for comparison [14], and also by the ORAC (oxygen radical absorbance capacity) assay, measuring light absorbance at $515 \mathrm{~nm}$ and comparing to a standard Trolox solution [15].

\section{Sensory analysis}

The sensory analysis was followed by Larmond (1977) [16]. Both dried chili paste with local herbs (formula A and B) were subjected to sensory testing by 40 untrained panelists in area of Khuean Srinagarindra National Park, Kanchanaburi province, using a 5-point hedonic scale (1=dislike extremely, $2=$ dislike, $3=$ neither like or nor like, $4=$ like, and 5=like extremely) to determine which was the most acceptable product as well as a 5-point just about right test $(1=$ not nearly enough, $3=$ at just about right and $5=$ much too). Approximately $1.5 \mathrm{~g}$ of dried chili paste was topped on $15 \mathrm{~g}$ of steamed rice and served to the panelists. A 3 digit number was coded on each container. The most acceptable formulation was selected for the consumer acceptability test. 


\section{Consumer acceptability test}

Consumer acceptability test was done according to Kotler (1997) [17]. Consumer ( $\mathrm{n}=300)$ were tested and interviewed at each of 3 locations; Kanchanaburi province $(n=100)$, Hua-Hin city $(n=100)$ and Samutsakhon province $(n=100)$. The method of central location testing was used and consumers were selected according to criteria of familiarity with the dried chili paste and age. Approximately $1.5 \mathrm{~g}$ of dried chili paste was topped on $15 \mathrm{~g}$ of steamed rice and served to the consumers. Consumers were asked to score the acceptability of dried chili paste with local herbs using a 9-point hedonic scale which varied from "dislike extremely" to "like extremely". After testing the product, consumers were interviewed to obtain demographic information regarding age, education, gender, occupation, income, how often they ate chili paste, where they normally bought chili paste and the factors which affect the buying behavior of chili paste. The interviews took approximately $15 \mathrm{~min}$. The protocol was approved by Mahidol University Central Institutional Review Board (MU-CIRB) (No.MU-CIRB 2015/047.2703). All participants were given written informed consent before joining the study.

\section{Statistical analysis}

Data were analyzed using an analysis of variance and t-test. Duncan multiple range test was used to determine significant difference among the various samples in triplicate. Data was analyzed using the software, Statistical Package for Social Science (SPSS) version 19 SPSS Inc., Chicago, II, USA at the 0.05 level.

\section{Results and discussion}

Sensory evaluations of 2 different formulas of dried chili paste with varying concentrations of chili were carried out by 40 panelists on a 5-point hedonic scale in relation to the product's appearance, color, overall liking, odor and flavor as well as a 5-point just about right test for spiciness, sweetness, saltiness and crispiness (as shown in Table 2). The results showed that there is no significant difference in terms of perceptions towards appearance, color, overall liking, odor and flavor between dried chili paste with formula $\mathrm{A}$ and formula $\mathrm{B}$. This might be due to the fact that the amount of ingredients used in both formulas is the same, except the amount of chili. Formula A contained $5.4 \%$ chili while formula B contained $3.7 \%$ chili. However, the dried chili paste with local herbs with $5.4 \%$ chili (formula A) seemed to be not nearly sweet enough. Therefore, dried chili paste with local herbs which contained 3.7 $\%$ chili (formula B) was selected for the consumer acceptability test due to the highest score on overall liking.

Table 2 Sensory evaluation of dried chili paste with local herbs at different levels of chili ${ }^{1}$.

\begin{tabular}{llll}
\hline & Parameters & Formula A & Formula B \\
\hline \multirow{2}{*}{ Before test } & Appearance,ns & $4.12 \pm 0.60$ & $4.00 \pm 0.59$ \\
& Color $^{2, n s}$ & $4.13 \pm 0.56$ & $4.02 \pm 0.61$ \\
\hline \multirow{5}{*}{ After test } & Overall liking, $^{2, n s}$ & $4.25 \pm 0.59$ & $4.30 \pm 0.52$ \\
& Odor $^{2, n s}$ & $4.25 \pm 0.59$ & $4.18 \pm 0.59$ \\
& Flavor $^{2, n s}$ & $4.25 \pm 0.71$ & $4.18 \pm 0.59$ \\
& Spicy, $^{3, n s}$ & $3.15 \pm 0.61$ & $3.02 \pm 0.35$ \\
& Sweetness $^{3}$ & $2.78 \pm 0.63 *$ & $2.83 \pm 0.50$ \\
& Saltiness $^{3, \text { ns }}$ & $3.02 \pm 0.52$ & $2.98 \pm 0.52$ \\
& Crispiness $^{3, \text { ns }}$ & $3.00 \pm 0.39$ & $3.07 \pm 0.35$ \\
\hline
\end{tabular}

\footnotetext{
${ }^{1}$ Results of 40 panelists

${ }^{2} 5$-point hedonic scale $(1=$ dislike extremely, $3=$ neither like or nor like and $5=$ like extremely)

${ }^{3}$ Just-about-right ( $1=$ not nearly enough, $3=$ just right and $5=$ much too)

${ }^{\text {ns }}$ No significant difference at $\mathrm{p}<0.05$ by one-way-ANOVA and Duncan's multiple range test

*Significant difference with 3 (just right) at $\mathrm{p}<0.05$ by One sample t-test
} 
The nutritional values and Thai RDI (Thai recommended daily intakes as percentage) of dried chili paste with local herbs which is presented in Table 3. The percentage of Thai RDI is based on a 2,000 calorie diet. The percentage of Thai RDI for total fat, total carbohydrate, fiber and sodium are $65 \mathrm{~g}, 300 \mathrm{~g}$, $25 \mathrm{~g}$ and 2,400 $\mathrm{mg}$, respectively [18]. One serving size (12 g) of product provided $23 \mathrm{kcal}$ of energy, 4.95 $\mathrm{g}$ of protein, $0.48 \mathrm{~g}$ of fat, $1.35 \mathrm{~g}$ of fiber and $403 \mathrm{mg}$ of sodium. This could be said that the product provides low energy and fat. For the sodium content, it was not too high (17\% Thai RDI). Moreover, the developed dried chili paste contains higher protein and fiber when compared other studies [19,20]. The total phenolic compounds and antioxidant activities of dried chili paste with local herbs were determined (as shown in Table 4). The dried chili paste with local herbs for one serving size (12 g) contained 26.64 mgGAE of total phenolic compounds and 67.25 and 2,345.35 $\mu \mathrm{mol}$ Trolox of antioxidant activities using DPPH and ORAC, respectively. According to Hemathulin and Techawongstien (2017), it found that the dried chili paste had higher total phenolic compounds and antioxidant activities than the herbals chili powder with grinded spices product. This was due to Wan-Prao-Hom, Kra-chai-Pran, Ka-Pa and Plai had higher total phenolic compounds and antioxidant activities than grinded spices which had been added in the herbals chili powder product [1,21]. However, there are many factors which affect the total phenolic compounds and antioxidant activities such as the location of the growing area, season and the processing methods. Moreover, the water activity of dried chili paste was 0.34 which was lower than Thai community standard level of water activity for dried chili paste (0.6) [22]. This was agreed with Beuchat [23] who presented that when water activity is lower than 0.6 , microbial cannot grow.

Table 3 Nutritional values and \% Thai RDI of dried chili paste (per $12 \mathrm{~g}$ (serving size)) ${ }^{1}$.

\begin{tabular}{lcc}
\hline Nutritional values & \multicolumn{2}{c}{ Chili paste } \\
\hline Energy (Kcal) & $23 \pm 0$ & $(1 \%)^{2}$ \\
Fat (g) & $0.48 \pm 0.02$ & $(1 \%)$ \\
Protein $(\mathrm{g})$ & $4.95 \pm 0.06$ & $(5 \%)$ \\
Carbohydrate $(\mathrm{g})$ & $3.93 \pm 0.07$ & $(17 \%)$ \\
Fiber (g) & $1.35 \pm 0.24$ & \\
Ash $(\mathrm{g})$ & $1.83 \pm 0.01$ & \\
Sodium (mg) & $403 \pm 8.34$ & \\
${ }^{1}$ mean \pm SD $(\mathrm{n}=3)$ & & \\
${ }^{2}$ Percent Thai RDI are based on a 2,000 calorie diet. The \% Thai RDI for total fat, total carbohydrate, fiber and \\
sodium are 65 g, 300 g, 25 g and 2,400 mg, respectively.
\end{tabular}

Table 4 Total phenolic compounds and antioxidant activity of dried chili paste with local herbs (per $12 \mathrm{~g}$ (serving size) $)^{1}$.

\begin{tabular}{lc}
\hline Total phenolic compound (mgGAE) & $26.64 \pm 0.56$ \\
\hline Antioxidant activities ( $\boldsymbol{\mu m o l}$ Trolox) & $67.25 \pm 2.32$ \\
$\quad$ DPPH assay & $2,345.35 \pm 114.98$ \\
ORAC assay & \\
\hline${ }^{1}$ mean \pm SD $(\mathrm{n}=3)$ & \\
$\mathrm{GAE}=$ gallic acid equivalent & \\
$\mathrm{TE}=$ trolox equivalent &
\end{tabular}


http://wjst.wu.ac.th

The demographic information of consumers in Kanchanaburi province, Hua-Hin city and Samutsakhon province showed that $46 \%$ was male while $54 \%$ was female. Most consumers fell in the 20 - 30 years age range (34\%). The vast majority of consumers' education level was below bachelor's degree $(55 \%)$. The occupation of consumers included merchant or housewife $(29 \%)$, employed $(25 \%)$, government officer $(19 \%)$, students $(14 \%)$ and self-employed $(13 \%)$. The personal income of most respondents was 305 - 610 US dollars (33\%). The results of consumption behavior and attitudes towards dried chili paste were presented that most consumers preferred dried chili paste $(89 \%)$ and consumed it 2 - 3 times per week (43\%). The favorite place for buying dried chili paste was at local markets $(51 \%)$. Moreover, the most important factor of dried chili paste purchase was taste $(48 \%)$ (Results are not shown). For sensory acceptability test of dried chili paste with local herbs using 9-point hedonic scale, the result showed that the score in appearance, color, herb flavor, taste, crispiness and overall liking were at the level of "like moderately" (Table 5). Furthermore, $92 \%$ percent of consumers found the dried chili paste with local herbs to be acceptable and $88 \%$ were willing to buy this product.

Table 5 Sensory acceptability test of dried chili paste with local herbs $(n=300)$.

\begin{tabular}{lc}
\hline Sensory attributes & Scores $^{\mathbf{1}}$ \\
\hline Appearance & 7.33 \\
Color & 7.31 \\
Herb flavor & 7.45 \\
Taste & 7.47 \\
Crispiness & 7.43 \\
Overall liking & 7.42 \\
\hline 9-point hedonic scale (1=dislike extremely, 5=neither like or nor like and 9=like extremely)
\end{tabular}

\section{Conclusions}

Dried chili paste with local herbs can provide an example of how community products from Kanchanaburi province can be used in food. In terms of nutritional values, one serving of dried chili paste with local herbs (12 g) provided low energy and fat, but it had moderate total phenolic and antioxidant activities. Consuming the developed dried chili paste with a side dish such as some vegetables or meats could help to complete one's required nutritional intake for a meal, including fiber. Therefore, this product might be able to be used to help to generate income for people living in the community. Finally, it could be used to create a greater awareness of local herb preservation in order for these plants to remain in the community.

\section{Acknowledgements}

The authors gratefully acknowledge the National Research Council of Thailand (NRCT) under Plant Genetic Conservation Project under the Royal Initiative of Her Royal Highness Princess Maha Chakri Sirindhorn (RSPG) for providing the funding and Institute of Nutrition, Mahidol University for providing the facilities to carry out this research. Moreover, the researchers would like to thank Electricity Generating Authority of Thailand, Kanchanaburi province for their cooperation. 
http://wjst.wu.ac.th

\section{References}

[1] S Charoenkiatkul, U Suttisansanee, W Srichamnong and N On-nom. Health benefit, food safety and product development of local plants at conserved area of Plant Genetic Conservation Project under the Royal Initiative of Her Royal Highness Princess Maha Chakri Sirindhorn, Kanchanaburi Province, Report. Institute of Nutrition, Mahidol University, Thailand, 2014.

[2] O Pengcharoen. Technology Chao Ban. Matichon Press, Bangkok, Thailand. 2002, p. 42-3.

[3] A Thiengsusuk, W Chaijaroenkul and K Na-Bangchang. Antimalarial activities of medicinal plants and herbal formulations used in Thai traditional medicine. Parasitology 2013; 112, 1475-81.

[4] S Tewtrakul and S Subhadhirasakul. Anti-allergic activity of some selected plants in the Zingiberaceae family. J. Ethnopharmacol. 2007; 109, 535-8.

[5] AA Elzaawely, TD Xuan and S Tawata. Essential oils, kava pyrenes and phenolic compounds from leaves and rhizomes of Alpinia zerumbet (Pers.) B.L. Burtt. \& R.M. Sm. and their antioxidant activity. Food Chem. 2007; 103, 486-94.

[6] EWC Chan, YY Lim and SK Wong. Antioxidant properties of ginger leaves: An overview. Free Radic. Antioxid. 2011; 1, 6-16.

[7] EWC Chan, YY Lim and TY Lim. Total phenolic content and antioxidant activity of leaves and rhizomes of some ginger species in Peninsular Malaysia. Gard. Bull. Sing. 2007; 59, 47-58.

[8] A Ghasemzadeh, HZE Jaafar and A Rahmat. Identification and concentration of some flavonoid components in Malaysian young ginger (Zingiber officinale Roscoe) varieties by a high performance liquid chromatography method. Molecules 2010; 15, 6231-433.

[9] LJ Jing, M Mohamed, A Rahmat and MFA Bakar. Phytochemicals, antioxidant properties and anticancer investigations of the different parts of several gingers species (Boesenbergia rotunda, Boesenbergia pulchella var attenuata and Boesenbergia armeniaca). J. Med. Plant Res. 2010; 4, $27-$ 32.

[10] V Chairgulprasert, S Prasertsongskun, S Junpra-ob and M Sangjun. Chemical constituents of essential oil, antioxidant and antibacterial activities from Elettariopsis curtisii Baker. Songklanakarin J. Sci. Tech. 2008; 30, 591-6.

[11] K Suriya and C Worasuwanaruk. Development of protein bar from brown rice and whey protein on physical and chemical properties of product. FST CMU Res. Exerc. J. 2016; 2016, 1-20.

[12] AOAC. Official Methods of Analysis, 20th ed. Association of Official Chemists International. Gaithersburg, Maryland, 2016.

[13] J Lu, H Zhao, J Chen, W Fan, J Dong, W Kong, J Sun, Y Cao and G Cai. Evolution of phenolic compounds and antioxidant activity during malting. J. Agric. Food Chem. 2007; 55, 10994-1001.

[14] T Katsuke. Screening for antioxidant activity in edible plant products: Comparison of low-density lipoprotein oxidantion assay, DPPH radical scavenging assay, and Folin-Ciocalteu assay. J. Agric. Food Chem. 2004; 52, 2391-6.

[15] B Ou, D Huang, MH Hampsch-Woodili, JA Flanagan and EK Deemer. Analysis of antioxidant activities of common vegetables employing oxygen radical absorbance capacity (ORAC) and ferric reducing power (FRAP) assays: A comparative study. J. Agric. Food Chem. 2002; 50, 3122-8.

[16] E Larmond. Laboratory Methods of Sensory Evaluation of Foods. Canada Communication Group, Ottawa, 1997.

[17] P Kotler. Marketing Management: Analysis, Planning, Implementation, and Control. $9^{\text {th }}$ ed. Prentice-Hall, New Jersey, 1997, p. 789.

[18] Public Health Ministerial Declaration No.182 in 1998 on Thai recommended daily intakes (Thai RDI), Available at http:/www.inmu.mahidol.ac.th/inmucal/app/5_Thai\%20RDI.pdf, accessed February 2018.

[19] K Punaaterkoon, Y Plaitho and A Manthon. Development of dry Nam Prik from Lotus seeds. VRU Res. Develop. J. Sci. Tech. 2016; 11, 109-17.

[20] S Ruangchai and S Tantakasem. Storage quality of Tamarind / Roselle Chili Paste. Univ. Thai Chamber Commerce J. 2011; 31, 89-98. 
http://wjst.wu.ac.th

[21] S Hemathulin and S Techawongstien. The effecting of chili varieties and spices on radical scavenging activity of herbals chili powder with grinded spices product. Khon Kaen Agric. J. 2017; 45, 272-8.

[22] Thai Industrial Standards Institute, Ministry of Industry. Thai Community Product Standard of Dried Chilli Paste (TCPS 130/2546), Available: http://app.tisi.go.th/otop/ pdf_file/tcps130_46.pdf, accessed February 2018.

[23] LR Beuchat. Microbial stability as affected by water activity. Cereal Food World 1981; 26, 345-9. 